\title{
Current Diagnosis of Venous Thrombo- embolism in Primary Care: A Clinical Practice Guideline from the American Academy of Family Physicians and the American College of Physicians
}

\author{
Amir Qaseem, MD, PbD, MHA ${ }^{1}$ \\ Vincenza Snow, MD, MS \\ Patricia Barry, $M D, M P H^{2}$ \\ E. Rodney Hornbake, $M D^{3}$ \\ Jonathan E. Rodnick, $M D^{4}$ \\ Timotby Tobolic, $M D^{5}$ \\ Belinda Ireland, $M D, M S^{6}$ \\ Jodi Segal, $M D^{7}$ \\ Eric Bass, $M D, M P H^{7}$ \\ Kevin B. Weiss, $M D, M P H^{8}$ \\ Lee Green, MD, MPH \\ Douglas K. Owens, MD, MS ${ }^{10}$ \\ the Joint American Academy \\ of Family Pbysicians/American \\ College of Pbysicians Panel on \\ Deep Venous Thrombosis/ \\ Pulmonary Embolism
}

AC see inside back cover or http://www. annfammed.org/AJCl.

Conflicts of interest: none reported

\section{CORRESPONDING AUTHOR}

Amir Qaseem, MD, PhD, MHA

American College of Physicians $190 \mathrm{~N}$ Independence Mall West Philadelphia, PA 19106

aqaseem@acponline.org

\begin{abstract}
This guideline summarizes the current approaches for the diagnosis of venous thromboembolism. The importance of early diagnosis to prevent mortality and morbidity associated with venous thromboembolism cannot be overstressed. This field is highly dynamic, however, and new evidence is emerging periodically that may change the recommendations. The purpose of this guideline is to present recommendations based on current evidence to clinicians to aid in the diagnosis of lower extremity deep venous thrombosis and pulmonary embolism.
\end{abstract}

Ann Fam Med 2007;5:57-62. DOI: 10.1370/afm.667.

\section{RECOMMENDATIONS}

\section{Recommendation 1}

Validated clinical prediction rules should be used to estimate pretest probability of venous thromboembolism (VTE), both deep venous thrombosis (DVT) and pulmonary embolism, and for the basis of interpretation of subsequent tests.

Good quality evidence supports the use of clinical prediction rules to establish pretest probability of disease. The Wells prediction rules for DVT and for pulmonary embolism (Tables 1 and 2) have been validated and are frequently used to estimate the probability of VTE before performing more definitive testing on patients. The Wells prediction rule performs better in younger patients without comorbidities or a history of VTE than it does in other patients. Physicians should use their clinical judgment in cases where a patient is older or presents with comorbidities.

\section{Recommendation 2}

In appropriately selected patients with low pretest probability of DVT or pulmonary embolism, obtaining a bigh-sensitivity D-dimer is a reasonable option, and if negative,

'American College of Physicians,

Philadelphia, Penn

${ }^{2}$ Merck Institute of Aging and Health, Gloucester Point, Va

${ }^{3}$ Private practice, Hadlyme, Conn

${ }^{4}$ University of California, San Francisco,

San Francisco, Calif

${ }^{5}$ Byron Family Medicine, Byron Center, Miss; American Academy of Family

Physicians, Leawood, Kan
${ }^{6} \mathrm{BJC}$ HealthCare, St. Louis, Mo; American Academy of Family Physicians, Leawood, Kan

${ }^{7}$ Johns Hopkins University School of Medicine, Baltimore, Md

${ }^{8}$ Hines Veterans Affairs Hospital and Northwestern University, Chicago, Ill ${ }^{9}$ University of Michigan, Ann Arbor, Mich ${ }^{10}$ Veterans Affairs Palo Alto Health Care System and Stanford University, Stanford, Calif 
indicates a low likelibood of VTE.

In selected patients who have a low pretest probability of VTE as defined by the Well prediction rules, a negative high-sensitivity D-dimer assay for VTE has sufficiently high negative predictive value to reduce the need for further imaging studies. Currently, enzyme-linked immunosorbent assay (ELISA), quantitative rapid ELISA, and advanced turbidimetric D-dimer determinations are highly sensitive assays (sensitivity $96 \%$ to $100 \%$ ) and their use is practical in diagnosis of VTE. Ddimer testing has the highest negative predictive value when used to exclude VTE in younger patients without associated comorbidity or history of VTE and with short duration of symptoms, because the Wells criteria more accurately predict a low pretest probability of VTE in such patients. In older patients, those with associated comorbidity, and long duration of symptoms, a D-dimer alone may not be sufficient to rule out VTE.

\section{Recommendation 3}

Ultrasound is recommended for patients with intermediate to bigh pretest probability of DVT in the lower extremities.

Use of ultrasound in diagnosing symptomatic thrombosis in the proximal veins of the lower limb is recommended for patients whose pretest probability of disease falls in the category of intermediate to high risk of DVT under the Wells prediction rule. Ultrasound is less sensitive in patients who have DVT limited to the calf; therefore, a negative ultrasound does not rule out DVT in these patients. Repeat ultrasound or venography may be required for patients who have suspected calf-vein DVT and a negative ultrasound and for patients who have suspected proximal DVT and an ultrasound that is technically inadequate or equivocal. Contrast venography is still considered the definitive test to rule out the diagnosis of DVT.

\section{Recommendation 4}

Patients with intermediate or bigh pretest probability of pulmonary embolism require diagnostic imaging studies.

For patients who have intermediate or high pretest probability of pulmonary embolism, imaging is essential. Possible tests include ventilation-perfusion (V/Q)
Table 1. Wells Prediction Rule for Diagnosing Deep Venous Thrombosis: Clinical Evaluation Table for Predicting Pretest Probability of Deep Vein Thrombosis

\section{Clinical Characteristic}

Score

Pextremities

ently bedridden $>3$ days or major surgery within 12 weeks requiring

the distribution of the deep venous system

tibial tuberosity)

Pitting edema confined to the symptomatic leg

Note: Clinical probability: low $\leq 0$; intermediate $1-2$; high $\geq 3$. In patients with symptoms in both legs, the more symptomatic leg is used. retest probability of deep-vein thrombosis in clinical management, pp 1795-1798, Copyright 2002,

Table 2. Wells Prediction Rule for Diagnosing Pulmonary Embolism: Clinical Evaluation Table for Predicting Pretest Probability of Pulmonary Embolism

\begin{tabular}{lc}
\hline Clinical Characteristic & Score \\
\hline Previous pulmonary embolism or deep vein thrombosis & +1.5 \\
Heart rate >100 beats per minute & +1.5 \\
Recent surgery or immobilization & +1.5 \\
Clinical signs of deep vein thrombosis & +3 \\
Alternative diagnosis less likely than pulmonary embolism & +3 \\
Hemoptysis & +1 \\
Cancer & +1 \\
\hline
\end{tabular}
(inical prediction rules and implicit assessment among patients with suspected pulmonary embolism, p 269-275, Copyright 2002, with permission from Elsevier. 
deep vein thromboses are uncommon and are outside the scope of this guideline. The annual incidence of VTE in the United States is 600,000 cases $^{1}$ and is increasing with the aging of the population. Twentysix percent of undiagnosed and untreated patients with pulmonary embolism will have a subsequent fatal embolic event, whereas another $26 \%$ will have a nonfatal recurrent embolic event that can eventually be fatal. ${ }^{2}$ Thus, the importance of early diagnosis to prevent mortality and morbidity associated with VTE cannot be overemphasized.

This guideline aims to present evidence-based recommendations for the diagnosis of lower extremity DVT and pulmonary embolism. The target audience for this guideline is all primary care physicians. The target patient population is all adults who have a probability of developing DVT or pulmonary embolism, including pregnant individuals.

\section{METHODS}

The guideline is based on a systematic review of the evidence as detailed in a comprehensive evidence report published in $2003^{3}$ and updated in the accompanying background paper by members of the Johns Hopkins University Evidence-based Practice Center that prepared the original report. ${ }^{4,5}$ Those papers contain substantial additional detail about the evidence for each of the recommendations in this guideline. The American Academy of Family Physicians (AAFP) nominated this topic to the Agency for Healthcare Research and Quality Evidence-based Practice Centers (EPC) program, and the American College of Physicians (ACP) supported the nomination. This document covers diagnosis and is the first of 2 guidelines, the second by Snow et al addresses management. ${ }^{6}$

This guideline's recommendations are based on the EPC review, which addressed the following questions on diagnosis formulated by the AAFP and ACP:

1. Are clinical prediction rules valuable for diagnosing DVT or pulmonary embolism, and does addition of the D-dimer assay improve the test characteristics of clinical prediction rules?

2. What are the test characteristics of D-dimer measurement alone when used for diagnosis or exclusion of lower extremity DVT or pulmonary embolism, and how does choice of assay affect the test characteristics?

3. What are the test characteristics of ultrasonography for diagnosis of DVT, including calf vein DVT?

4. What are the test characteristics of computed axial tomography (CT) for diagnosis of pulmonary embolism?

\section{CLINICAL PREDICTION RULES ALONE AND IN COMBINATION WITH D-DIMER ASSAY FOR DIAGNOSIS OF VTE}

A clinical prediction rule is used to calculate the pretest probability of VTE based on a clinical assessment of risk factors and physical findings. Of the various available prediction rules, the Wells prediction rules for DVT and pulmonary embolism ${ }^{7,8}$ were most frequently evaluated (17 of 19 studies for DVT ${ }^{7,9-24}$ and 3 of 8 for pulmonary embolism ${ }^{25-27}$ ). Individual clinical features are poorly predictive when not combined in a formal prediction rule. ${ }^{28}$

Eleven studies combined the Wells prediction rule with a D-dimer assay.* A systematic review concluded that patients with a low pretest probability and a negative D-dimer test had a 3-month incidence of DVT of $0.5 \%$, whereas those with a negative D-dimer test and moderate or high pretest probability had incidences of $3.5 \%$ and $21.4 \%$, respectively. ${ }^{30}$ A recent study of the Wells rule in primary care raised doubts about its negative predictive value, but the study included patients with recurrent DVT, and its implications are not yet clear. ${ }^{31}$

In summary, the evidence supports the use of a clinical prediction rule for establishing pretest probability of VTE. Combination of a D-dimer assay with a clinical prediction rule provides sufficient negative predictive value to reduce the need for further imaging studies in appropriately selected patients with low pretest probability of disease.

\section{TEST CHARACTERISTICS OF D-DIMER ASSAYS ALONE FOR DIAGNOSIS OF VTE}

Four systematic reviews ${ }^{4}$ evaluated the use of D-dimer testing alone (ie, without concomitant use of a clinical prediction rule) for diagnosis or exclusion of VTE. Two of these studies examined the use of D-dimer testing for excluding pulmonary embolism. These studies showed that both enzyme-linked immunosorbent assays (ELISA) and latex turbidimetric assays had a high sensitivity and a high negative predictive value for pulmonary embolism in patients with a low to moderate clinical probability of the disease (using a D-dimer cutoff of $500 \mathrm{ng} / \mathrm{mL}$ ). ${ }^{32,33}$ Specificity decreased, however, for patients with associated comorbidity, older age, and longer duration of symptoms. Stein et al's meta-analysis of D-dimer assays for diagnosis of DVT or pulmonary embolism using ELISA found pooled specificities ranged from $40 \%$ to $50 \%{ }^{34}$

In summary, the evidence suggests that a negative highly sensitive D-dimer test can help exclude the diagnosis of proximal DVT and pulmonary embolism

* References 9, 14, 15 17-19,22,23,26, 27, 29. 
in relatively healthy younger patients with short duration of symptoms who have a low pretest probability of VTE. There is variation in the sensitivity of D-dimer assays, however, and clinicians should be informed about the type of D-dimer assay used in their clinical setting relative to the population being tested and type of assay being used.

\section{TEST CHARACTERISTICS OF ULTRASONOGRAPHY FOR DIAGNOSIS OF DVT}

The EPC review found sensitivities of $89 \%$ to $96 \%$ and specificities of $94 \%$ to $99 \%$ for ultrasonography in the diagnosis of symptomatic thrombosis in the proximal veins of the lower extremity. ${ }^{12,35-41}$ Sensitivity was lower ( $47 \%$ and $62 \%$ ) for diagnosis of thrombi in proximal veins in asymptomatic patients. ${ }^{12,38}$ There was also variation in sensitivity ( $73 \%$ to $93 \%)$ in symptomatic patients with DVT in the calf. ${ }^{37-39}$ For asymptomatic patients, however, sensitivities for detecting DVT limited to the calf were approximately $50 \%$. All of the reviews used contrast venography as the reference standard point for inclusion criterion.

Hence, ultrasonography has high sensitivity and specificity for diagnosing proximal DVT of the lower extremity in symptomatic patients. Though specificity is maintained, sensitivity is diminished in patients who are asymptomatic or who have DVT in the calf.

\section{TEST CHARACTERISTICS OF HELICAL COMPUTED AXIAL TOMOGRAPHY FOR DIAGNOSIS OF PULMONARY EMBOLISM}

The systematic reviews for use of helical CT in diagnosis of pulmonary embolism reported a wide range of summary sensitivities (66\% to $93 \%$ ) but a narrow range of summary specificities ( $89 \%$ to $98 \%) .{ }^{42}$ Inclusion criteria and reference standards varied across the different reviews, and heterogeneity was high across individual studies. Segal and colleagues performed their own systematic review including only prospective studies and those that uniformly applied pulmonary arteriography as the reference standard, and they confirmed the finding of wide variation in sensitivity (45\% to $100 \%)$ and specificity $(78 \%$ to $100 \%){ }^{4}$

Interpretation of this evidence is controversial because of such factors as substantial referral bias associated with the published evidence. More importantly, the literature has lagged behind rapid recent advances in CT technology. The authors of the EPC report estimate that for diagnosis of pulmonary embolism, helical CT has at best a sensitivity of $90 \%$ and specificity of 95\% compared with conventional pulmonary arteriog- raphy. Data published after the EPC review was completed suggest that current-generation multidetector CT technology may offer significantly higher sensitivity and similar specificity to the technology assessed in the EPC review. ${ }^{43}$ Even so, 2 recent systematic reviews conclude that helical CT alone may not be sufficiently sensitive to exclude pulmonary embolism in patients who have relatively high pretest probability. ${ }^{44,45}$ Further imaging studies are likely needed in patients who have a high pretest probability of pulmonary embolism and a negative CT scan; options include single or sequential ultrasound assessment of the lower extremities or pulmonary angiography.

\section{SUMMARY}

Strong evidence supports the use of clinical prediction rules to establish pretest probability of VTE before further testing. Use of a high-sensitivity D-dimer assay in patients who have a low pretest probability of VTE has a high negative predictive value; it is highest for younger patients with low pretest probability, no associated comorbidity or previous DVT, and a short duration of symptoms. There is strong evidence supporting the use of ultrasonography for diagnosing proximal DVT in symptomatic patients; sensitivity is much lower in asymptomatic patients and for detecting calf vein DVT. Recent results suggest that newer CT technology for diagnosis of pulmonary embolism might have a higher sensitivity and specificity than seen in previous studies. In addition, it is likely that accuracy of CTs will improve with time as the technology evolves further.

To read or post commentaries in response to this article, see it online at http://www.annfammed.org/cgi/current/full/5/1/57.

Key words: Deep vein thrombosis; pulmonary embolism; thromboembolism, venous; practice guidelines; recommendations

Submitted May 1, 2006; accepted October 3, 2006.

This guideline was approved by the American College of Physicians Board of Regents on April 4, 2006; and approved by the American Academy of Family Physicians Board of Directors on March 28, 2006.

Funding support: Financial support for the development of this guideline comes exclusively from the American College of Physicians and American Academy of Family Physicians operating budgets.

Disclaimer: No statement in this article should be construed as an official position of the Agency for Healthcare Research and Quality or the US Department of Health and Human Services.

Notice: Clinical practice guidelines are "guides" only and may not apply to all patients and all clinical situations. Thus, they are not intended to override clinicians' judgment. All American College of Physicians' clinical practice guidelines are considered automatically withdrawn or invalid 5 years after publication or once an update has been issued. 
Joint American Academy of Family Physicians/American College of Physicians Panel on Deep Venous Thrombosis/Pulmonary Embolism: Clinical Efficacy and Assessment Subcommittee of the American College of Physicians: Douglas K. Owens, MD, MS, Chair; Mark Aronson, MD; Donald E. Casey Jr, MD, MPH, MBA; J. Thomas Cross, Jr, MD, MPH; Nancy C. Dolan, MD; Nick Fitterman, MD; E. Rodney Hornbake, MD; Paul Shekelle, MD, PhD; Katherine D. Sherif, MD; Kevin Weiss, MD, MPH (Immediate Past Chair). Commission on Science of the American Academy of Family Physicians: Eric M. Wall, MD, MPH, Chair; Kevin A. Peterson, MD, MPH; James M. Gill, MD; Robert C. Marshall, MD, MPH; Jonathan E. Rodnick, MD; Kenneth G. Schellhase, MD, MPH; Steven W. Strode, MD, MEd, MPH; Kurtis S. Elward, MD, MPH; James W. Mold, MD, MPH; Jonathan L. Temte, MD, PhD; Frederick M. Chen, MD, MPH; Thomas F. Koinis, MD; Donya A. Powers, MD; Karl M. Kochendorfer, MD; Peter John Oppelt; Herbert F. Young, MD, MA; Bellinda K. Schoof, MHA.

\section{References}

1. Anderson FA, Jr., Wheeler HB, Goldberg RJ, et al. A populationbased perspective of the hospital incidence and case-fatality rates of deep vein thrombosis and pulmonary embolism. The Worcester DVT Study. Arch Intern Med. 1991;151:933-938.

2. Barritt DW, Jordan SC. Anticoagulant drugs in the treatment of pulmonary embolism. A controlled trial. Lancet. 1960;1:1309-1312.

3. Segal J, Eng J, Jenckes M. Diagnosis and Treatment of Deep Venous Thrombosis and Pulmonary Embolism. Evidence Report/Technology Assessment. Rockville, MD: Prepared by the Johns Hopkins Evidence-based Practice Center under Contract No. 290-97-0007. 2003. Publication No. 03-E016.

4. Segal J, Eng J, Tamariz L, Bass E. Review of the evidence on diagnosis of deep venous thrombosis and pulmonary embolism. Ann Fam Med. 2007;5:63-73.

5. Segal JB, Streiff MB, Hoffman LV, Thornton K, Bass EB. Management of venous thromboembolism: a systematic review for a practice guideline. Ann Intern Med. 2007;146:211-222.

6. Snow V, Qaseem A, Barry P, et al. Management of venous thromboembolism in primary care: a clinical practice guideline from the American College of Physicians and the American Academy of Family Physicians. Ann Intern Med. 2007;146:204-210.

7. Wells PS, Anderson DR, Bormanis J, et al. Value of assessment of pretest probability of deep-vein thrombosis in clinical management. Lancet. 1997;350:1795-1798.

8. Chagnon I, Bounameaux H, Aujesky D, et al. Comparison of two clinical prediction rules and implicit assessment among patients with suspected pulmonary embolism. Am J Med. 2002;113:269-275.

9. Cornuz J, Ghali WA, Hayoz D, et al. Clinical prediction of deep venous thrombosis using two risk assessment methods in combination with rapid quantitative D-dimer testing. Am J Med. 2002;112: 198-203.

10. Anderson DR, Wells PS, Stiell I, et al. Thrombosis in the emergency department: use of a clinical diagnosis model to safely avoid the need for urgent radiological investigation. Arch Intern Med. 1999;159:477-482

11. Kraaijenhagen RA, Piovella F, Bernardi E, et al. Simplification of the diagnostic management of suspected deep vein thrombosis. Arch Intern Med. 2002;162:907-911.

12. Wells PS, Lensing AW, Davidson BL, Prins MH, Hirsh J. Accuracy of ultrasound for the diagnosis of deep venous thrombosis in asymptomatic patients after orthopedic surgery. A meta-analysis. Ann Intern Med. 1995;122:47-53.

13. Dryjski M, O’Brien-Irr MS, Harris LM, Hassett J, Janicke D. Evaluation of a screening protocol to exclude the diagnosis of deep venous thrombosis among emergency department patients. J Vasc Surg. 2001;34:1010-1015.
14. Anderson DR, Wells PS, Stiell I, et al. Management of patients with suspected deep vein thrombosis in the emergency department: combining use of a clinical diagnosis model with D-dimer testing. J Emerg Med. 2000;19:225-230.

15. Funfsinn N, Caliezi C, Biasiutti FD, et al. Rapid D-dimer testing and pre-test clinical probability in the exclusion of deep venous thrombosis in symptomatic outpatients. Blood Coagul Fibrinolysis. 2001:12:165-170.

16. Constans J, Nelzy ML, Salmi LR, et al. Clinical prediction of lower limb deep vein thrombosis in symptomatic hospitalized patients. Thromb Haemost. 2001;86:985-990.

17. Kearon C, Ginsberg JS, Douketis J, et al. Management of suspected deep venous thrombosis in outpatients by using clinical assessment and D-dimer testing. Ann Intern Med. 2001;135:108-111.

18. Aschwanden M, Labs KH, Jeanneret C, Gehrig A, Jaeger KA. The value of rapid $\mathrm{D}$-dimer testing combined with structured clinical evaluation for the diagnosis of deep vein thrombosis. J Vasc Surg. 1999;30:929-935.

19. Schutgens RE, Ackermark P, Haas FJ, et al. Combination of a norma D-dimer concentration and a non-high pretest clinical probability score is a safe strategy to exclude deep venous thrombosis. Circulation. 2003;107:593-597.

20. Shields GP, Turnipseed S, Panacek EA, et al. Validation of the Canadian clinical probability model for acute venous thrombosis. Acad Emerg Med. 2002;9:561-566.

21. Tick LW, Ton E, van Voorthuizen T, et al. Practical diagnostic management of patients with clinically suspected deep vein thrombosis by clinical probability test, compression ultrasonography, and Ddimer test. Am J Med. 2002;113:630-635.

22. Ruiz-Gimenez N, Friera A, Artieda P, et al. Rapid D-dimer test combined a clinical model for deep vein thrombosis. Validation with ultrasonography and clinical follow-up in 383 patients. Thromb Haemost. 2004;91:1237-1246.

23. Ilkhanipour $\mathrm{K}$, Wolfson $A B$, Walker $\mathrm{H}$, et al. Combining clinical risk with $\mathrm{D}$-dimer testing to rule out deep vein thrombosis. J Emerg Med. 2004;27:233-239.

24. Wells PS, Anderson DR, Bormanis J, et al. Application of a diagnostic clinical model for the management of hospitalized patients with suspected deep-vein thrombosis. Thromb Haemost. 1999;81:493-497.

25. Wells PS, Ginsberg JS, Anderson DR, et al. Use of a clinical model for safe management of patients with suspected pulmonary embolism. Ann Intern Med. 1998;129:997-1005.

26. Wells PS, Anderson DR, Rodger M, et al. Derivation of a simple clinical model to categorize patients probability of pulmonary embolism: increasing the models utility with the SimpliRED Ddimer. Thromb Haemost. 2000;83:416-420.

27. Wells PS, Anderson DR, Rodger $M$, et al. Excluding pulmonary embolism at the bedside without diagnostic imaging: management of patients with suspected pulmonary embolism presenting to the emergency department by using a simple clinical model and ddimer. Ann Intern Med. 2001;135:98-107.

28. Goodacre S, Sutton AJ, Sampson FC. Meta-analysis: The value of clinical assessment in the diagnosis of deep venous thrombosis. Ann Intern Med. 2005;143:129-139.

29. Lennox AF, Delis KT, Serunkuma $S$, et al. Combination of a clinical risk assessment score and rapid whole blood D-dimer testing in the diagnosis of deep vein thrombosis in symptomatic patients. J Vasc Surg. 1999:30:794-803.

30. Fancher TL, White RH, Kravitz RL. Combined use of rapid D-dimer testing and estimation of clinical probability in the diagnosis of deep vein thrombosis: systematic review. BMJ. 2004;329:821.

31. Oudega R, Hoes AW, Moons KG. The Wells rule does not adequately rule out deep venous thrombosis in primary care patients. Ann Intern Med. 2005;143:100-107. 
32. Brown MD, Lau J, Nelson RD, Kline JA. Turbidimetric D-dimer test in the diagnosis of pulmonary embolism: a metaanalysis. Clin Chem 2003;49:1846-1853.

33. Brown MD, Rowe BH, Reeves MJ, Bermingham JM, Goldhaber SZ. The accuracy of the enzyme-linked immunosorbent assay D-dimer test in the diagnosis of pulmonary embolism: a meta-analysis. Ann Emerg Med. 2002;40:133-144.

34. Stein PD, Hull RD, Patel KC, et al. D-dimer for the exclusion of acute venous thrombosis and pulmonary embolism: a systematic review. Ann Intern Med. 2004;140:589-602

35. White RH, McGahan JP, Daschbach MM, Hartling RP. Diagnosis of deep-vein thrombosis using duplex ultrasound. Ann Intern Med. 1989;111:297-304

36. Becker DM, Philbrick JT, Abbitt PL. Real-time ultrasonography for the diagnosis of lower extremity deep venous thrombosis. The wave of the future? Arch Intern Med. 1989;149:1731-1734.

37. Cogo A, Lensing AW, Wells P, Prandoni P, Buller HR. Noninvasive objective tests for the diagnosis of clinically suspected deep-vein thrombosis. Haemostasis. 1995;25:27-39.

38. Kearon C, Julian JA, Newman TE, Ginsberg JS. Noninvasive diagnosis of deep venous thrombosis. McMaster Diagnostic Imaging Practice Guidelines Initiative. Ann Intern Med. 1998;128:663-677.
39. Gottlieb RH, Widjaja J, Tian L, Rubens DJ, Voci SL. Calf sonography for detecting deep venous thrombosis in symptomatic patients: experience and review of the literature. J Clin Ultrasound. 1999;27:415-420.

40. Mustafa BO, Rathbun SW, Whitsett TL, Raskob GE. Sensitivity and specificity of ultrasonography in the diagnosis of upper extremity deep vein thrombosis: a systematic review. Arch Intern Med. 2002:162:401-404.

41. Kassai B, Boissel JP, Cucherat $M$, et al. A systematic review of the accuracy of ultrasound in the diagnosis of deep venous thrombosis in asymptomatic patients. Thromb Haemost. 2004;91:655-666.

42. Rathbun SW, Raskob GE, Whitsett TL. Sensitivity and specificity of helical computed tomography in the diagnosis of pulmonary embolism: a systematic review. Ann Intern Med. 2000;132:227-232.

43. Winer-Muram HT, Rydberg J, Johnson MS, et al. Suspected acute pulmonary embolism: evaluation with multi-detector row CT versus digital subtraction pulmonary arteriography. Radiology. 2004;233:806-815

44. Roy PM, Colombet I, Durieux P, et al. Systematic review and metaanalysis of strategies for the diagnosis of suspected pulmonary embolism. BMJ. 2005;331:259.

45. Quiroz R, Kucher N, Zou KH, et al. Clinical validity of a negative computed tomography scan in patients with suspected pulmonary embolism: a systematic review. JAMA. 2005;293:2012-2017. 